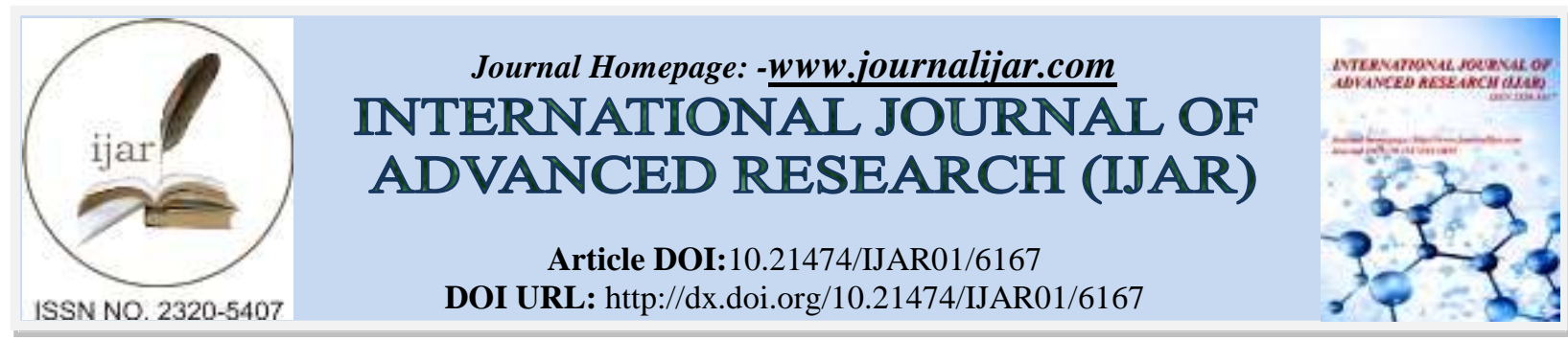

RESEARCH ARTICLE

\title{
IMPACT OF PERIODONTAL DISEASE ON QUALITY OF LIFE AMONG PERIODONTAL PATIENTS IN RIYADH.
}

Reem Al Kattan ${ }^{1}$, Noaf Al Shibani ${ }^{1}$, Ghadah AlEnazi ${ }^{2}$, Demah AINafa ${ }^{3}$ and Hanadi AL Zahrani ${ }^{3}$.

1. Department of Periodontics and Community Dentistry, College of Dentistry, King Saud University, Riyadh, Saudi Arabia

2. Rabwa primary healthcare center, Ministry of Health, Riyadh, Saudi Arabia

3. Department of dentistry, King Saud University.

\section{Manuscript Info}

(..........................

Manuscript History

Received: 25 October 2017

Final Accepted: 27 November 2017

Published: December 2017

Keywords:-

Adult; periodontal disease; oral health; quality of life; Riyadh.

\section{Abstract}

Background: Periodontitis typically affects the supporting tissues of the teeth, and potentially could produce impacts on individual's oral health-related quality of life (OHRQoL)

Objective: To assess the impact of periodontal health status on quality of life among subjects diagnosed with periodontal disease in a university setting in Riyadh, Saudi Arabia.

Material and methods: The study included asimple random sample of 25 adults referred to the periodontal clinics at the College of Dentistry, King Saud University. The Arabic short-form version of the oral health impact profile (OHIP-14) was used to assess oral health-related quality of life. Subjects enrolled in this cross-sectional study were requested to fill the OHIP-14questionnaire and underwent a comprehensive periodontal clinical examination. Please write briefly the clinical measurements taken. Clinical examination was conducted. The oral hygiene and periodontal status of all teeth except third molars were recorded. Probing pocket depth (PPD), clinical attachment level (CAL), and bleeding on probing (BOP) were assessed at six points per tooth.

Results: the impact of periodontal disease on the patient's quality of life was statistically significant in two domains, physical pain $(P$ value $.004)$ and psychological disability $(P$ value .001$)$. The severity of periodontal disease did not show a negative impact on functional limitation.

Conclusion: By using the Arabic version of the OHIP -14 index, periodontal disease had a negative impact on quality of life.

Copy Right, IJAR, 2017. All rights reserved.

\section{Introduction:-}

Periodontal disease is a common inflammatory disease worldwide. In Saudi Arabia, 30.1\%-50.8\% of people aged between 25 and 55years old have some degree of periodontal disease. ${ }^{1}$

Periodontitis typically affects the supporting tissues of the teeth, and potentially could produce impacts on individual's oral health-related quality of life (OHRQoL) ${ }^{2}$ Chronic forms of periodontal diseases have long been viewed as silent diseases that are not noticed by affected patients. Traditional clinical studies on periodontal disease 
were concerned about the clinico-pathological mechanisms of the periodontal disease despite its effect on the patient. However, recent findings indicate a considerable impact of periodontitis on oral health related quality of life $(\mathrm{OHQoL})^{3}$. These studies that focus on the biopsychosocial disease effects have shown that periodontal disease can exert both psychological and social problems ${ }^{4}$.

Quality of Life Research Unit at the University of Toronto defines quality of life as "The degree to which a person enjoys the important possibilities of his or her life $e^{\prime 5}$. Quality of life is directly affected by oral health.The term "oral health-related quality of life" (OHQoL) has had numerous definitions, and has been described as "the extent to which oral disorders affect functioning and psycho-social wellbeing ${ }^{\prime \prime}$.

Specific instruments to assess oral health-related quality of life have been developed. Most of the assessments capture attributes ranging from the domains of symptoms e.g. (pain, comfort), physical aspects (eating, speech, appearance), psychological aspects (confidence, mood, personality), to social aspects, such as social life, work and finances ${ }^{3}$. Examples on currently available oral specific health status measures include; Social Impacts of Dental Disease by Cushing et al, 1986, Geriatric Oral Health Assessment Index by Atchison and Dolan 1990, Dental Impact Profile by Strauss and Hunt 1993, Oral Health Impact Profile (OHIP) by Slade and Spencer 1994, Subjective Oral Health Status Indicators by Locker and Miller 1994, Dental Impact on Daily Living by Leao and Sheiham 1996, Oral Impacts on Daily Performances by Adulyanon and Sheiham 1997, and Oral Health Related Quality of Life-UK(OHQoL-UK) by McGrath and Bedi $2000^{7}$.

OHIP is a 49 item measure, with statements divided into seven theoretical domains, namely functional limitation, pain, psychological discomfort, physical disability, psychological disability, social disability and, handicap. A Likert response format $(0=$ never, $1=$ Hardly,ever, $2=$ occasionally, $3=$ fairly often, $4=$ very often $)$ is used. Frequency of impacts is calculated by summing the reported negative impacts (i.e., fairly often or very often) across the 49 statements. The short version of OHIP(OHIP-14) contains 14 items derived from the 49 - item OHIP, and appears to have good validity and reliability properties in measuring the oral health related quality of life ${ }^{6-8}$.

The UK oral health-related quality of life measure is also widely used in the literature. This measure was developed based on the UK public's perceptions of the key areas of oral health-related quality of life. Using this measure, the patients are asked to rate the impact of their oral health on 16 key areas of oral health-related quality of life. Possible response categories range from "very bad effect" to "very good effect". Scores were derived from response categories to each question: "very bad (score 1), bad (score 2), none (score 3), good (score 4) to very good (score 5)', Summing up responses from each of the16 items can therefore produce overall OHQoL-UK scores ranging from 16 (representing poorest oral health-related quality of life possible) to 80 (best oral health-related quality of life possible $)^{9}$.

In a UK study in 2004, it was shown that the periodontal status of 200 patients had a significant impact on life quality, using the OHQoL-UK index ${ }^{9}$. In 2010, 401 patients with periodontal disease voluntarily completed the OHIP-14, and the result was patients with aggressive periodontitis achieved the highest impact scores ${ }^{10}$. Four hundred individuals with periodontal disease in Jordan were clinically examined and selected to fill the OHIP-14, and there was statistically significant association between the severity of periodontal disease and OHIP-14 scores ${ }^{11}$. A recent Brazilian study has concluded that the loss of periodontal supporting structures has negative effects on the masticatory performance and quality of life, as shown by the scores of the Brazilian version of the OHIP-14 ${ }^{12}$. In addition, OHQoL has been shown to improve with non-surgical periodontal therapy, according to the OHIP-14 scores, among 65 Chinese adults with moderate to severe chronic periodontitis ${ }^{13}$. Another study has shown that patients with periodontal disease reported significantly more impacts on their quality of life than dentally healthy patients. After root surface debridement, the impact was significantly reduced, as measured using the OHIP-14 ${ }^{6}$.

A recent Brazilian study, that included 151 periodontal patients, had shown that periodontal disease exhibited negative impacts on the psychological discomfort and physical disability domains of the OHIP-14 index ${ }^{14}$. Another recent study that examined 443 subjects clinically and radiographically, have concluded that patients with severe marginal bone loss experienced worse quality of life compared to individuals with no/minor marginal bone loss. The oral health related quality of life was assessed using the Swedish short- form version of oral health impact profile ${ }^{2}$. 
Therefore, the objective of our study was to assess the impact of periodontal health status on quality of life among subjects diagnosed with periodontal disease, using the short version of the oral health impact profile (OHIP-14), in a university setting in Riyadh, Saudi Arabia.

\section{Material and Methods:-}

Study Sample:-

A simple random sample of 25 adults, referred to the periodontal clinics at the College of Dentistry, King Saud University, was selected. The inclusion criteria include: adult patients aged 18 years or older, diagnosed with periodontal disease, and have 15 teeth or more present. The exclusion criteria include; presence of psychological or mental disorder, the need for antibiotic coverage during routine dental procedures, the presence of a removable denture, and the presence of a symptomatic oral lesion.

\section{Data Collection :-}

This study was approved by the College of Dentistry Research Center (CDRC) of King Saud University. Subjects enrolled in this cross-sectional study were requested to fill a questionnaire and undergo a comprehensive periodontal clinical examination. The questionnaire included questions on the patient's age (years), sex, marital status, level of education, social history, history of chronic conditions, regular use of medications at the time of data collection, smoking status, frequency of brushing, and previous dental visits and periodontal treatment during the past 6 months. The impact of oral health on patient life quality was assessed by the use of an Arabic version of Oral Health Impact Profile-14 index (OHIP-14). The Arabic version of the index was validated in a previous study in Jordan ${ }^{11}$.

The OHIP-14 is a self-administered questionnaire that measures OHQoL using 14 items to record measures of seven dimensions; functional limitation, physical pain, psychological discomfort, physical disability, psychological disability, social disability, and handicap. Each dimension is measured by two questions. Subjects were asked how frequently they had experienced negative impacts in these dimensions. Responses to the items were recorded by using a five-point Likert scale: 0, never; 1, hardly ever; 2, occasionally; 3, fairly often; 4, very often. The answers of often and always had an impact and answers of sometimes, rarely and never had no impact ${ }^{8}$. An impact on each of the seven dimensions of the OHIP-14 was calculated by summing up all the responses to the two questions that represent each of these dimensions. The overall scores for the OHIP-14 were obtained by summing all responses for each subject, and thus they ranged from 0 to 56 points.

Clinical examination was conducted by one examiner, who was a periodontal specialist. The oral hygiene and periodontal status of all teeth except third molars were recorded. Probing pocket depth (PPD), clinical attachment level (CAL), and bleeding on probing (BOP) were assessed at six points per tooth. Plaque was recorded as present or absent at four sites per tooth. The mean PPD, mean CAL, the bleeding and plaque scores were calculated for each participant. In addition, the number of teeth with $\mathrm{PPD} \geq 3 \mathrm{~mm}, \mathrm{PPD} \geq 5 \mathrm{~mm}, \mathrm{PPD} \geq 7 \mathrm{~mm}$, and the number of teeth with CAL of 3,4 , and $5 \mathrm{~mm}$ or more were also be measured for each patient.

\section{Statistical Analysis:-}

The Statistical Package for Social Sciences (SPSS, version 22) was used for data processing and data analysis. The characteristics of variables were described using frequency distribution, mean and standard deviation. Student'TTest was used to compare means of continuous variable between two different groups. The Pearson Correlation analysis wasused to find the correlation between the degree of periodontal disease severity and the differences in the OHIP-14 scores. A $p$ value of less than 0.05 was considered statistically significant

\section{Results:-}

\section{Participant Characteristics:-}

This study comprised 25 adults (11men and 14women) aged between 23 and 80 years, with a mean age of 49 years. Their sociodemographic, clinical, and other relevant characteristics are shown in Table 1. Fewer than half of our sample $(40.0 \%)$ had an education of less than high school. Around half of the sample (48\%) seeks dental treatment only for pain. $88 \%$ of the participants have reported no history of previous periodontal treatment. 
Table 1:-Sociodemographic, Clinical, and other Relevant Characteristics of Participants

\begin{tabular}{|c|c|c|}
\hline variable & Frequency & Percentage \\
\hline \multicolumn{3}{|l|}{ Age (years) } \\
\hline$\leq 50$ & 17 & 68 \\
\hline $50>$ & 8 & 32 \\
\hline \multicolumn{3}{|l|}{ Gender } \\
\hline $\mathrm{M}$ & 11 & 44 \\
\hline $\mathrm{F}$ & 14 & 56 \\
\hline \multicolumn{3}{|c|}{ Marital status } \\
\hline Single & 2 & 8 \\
\hline Married & 23 & 92 \\
\hline \multicolumn{3}{|l|}{ Education } \\
\hline Below HS* & 10 & 40 \\
\hline $\mathrm{HS}$ & 4 & 16 \\
\hline Above HS & 11 & 44 \\
\hline \multicolumn{3}{|l|}{ Family size } \\
\hline $5<$ & 2 & 8 \\
\hline$\geq 5$ & 23 & 92 \\
\hline \multicolumn{3}{|l|}{ Smoking } \\
\hline Yes & 2 & 8 \\
\hline No & 21 & 84 \\
\hline \multicolumn{3}{|c|}{ Systemic disease } \\
\hline Yes & 10 & 40 \\
\hline No & 15 & 60 \\
\hline \multicolumn{3}{|c|}{ Frequency of brushing/day } \\
\hline$\leq 1$ & 9 & 36 \\
\hline$>1$ & 16 & 64 \\
\hline \multicolumn{3}{|c|}{ Frequency of dental visit } \\
\hline Regular & 8 & 32 \\
\hline irregular & 5 & 20 \\
\hline For pain & 12 & 48 \\
\hline \multicolumn{3}{|c|}{ History of periodontal treatment } \\
\hline Yes & 3 & 12 \\
\hline No & 22 & 88 \\
\hline
\end{tabular}

* HS;High School

Oral Hygiene and Periodontal Status:-

The oral hygiene and periodontal status of participants according to the participants' age is shown in Table 2 . The severity and extent of periodontal disease did not show any significant relation with the advancing age.

Table 2:-Oral Hygiene and Periodontal Status of Participants by Age

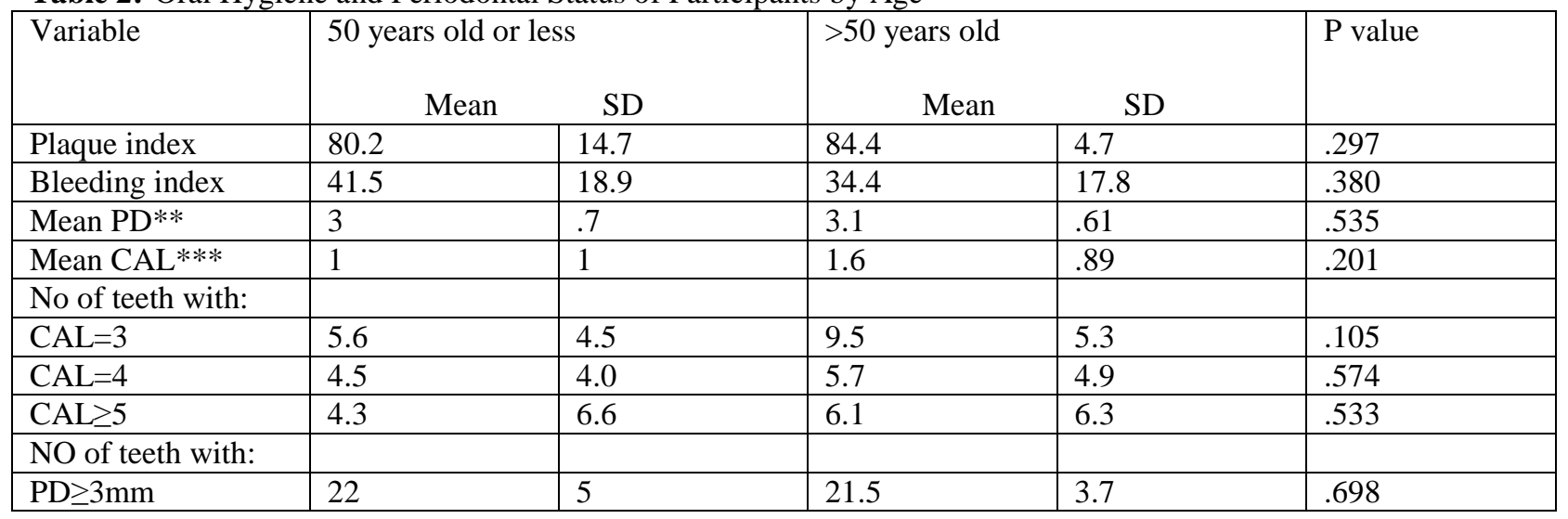




\begin{tabular}{|l|l|l|l|l|l|}
\hline $\mathrm{PD} \geq 5 \mathrm{~mm}$ & 11 & 6 & 9.0 & 5.9 & .437 \\
\hline $\mathrm{PD} \geq 7 \mathrm{~mm}$ & 3 & 2.9 & 3.7 & 4.0 & .753 \\
\hline
\end{tabular}

*SD;standard deviation, $* * \mathrm{PD} ;$ pocket depth, $* * * \mathrm{CAL} ;$ clinical attachment loss

Impact of periodontal disease on QoL:-

Table 3 shows the distribution of responses to the OHIP-14 items for all subjects. $24 \%(n=6)$ of the patients have reported that they felt nervous very often, while $92 \%(n=23)$ never had trouble pronouncing words.

It was found that the impact of periodontal disease on the patient's quality of life was statistically significant in two domains, namely physical pain $(P$ value .004$)$ and psychological disability (P value .001) (Table 4$)$. The severity of periodontal disease in this current study did not show a negative impact on functional limitation. In general, the total OHIP-14 scores were significantly related to the number of teeth with pocket depths of $5 \mathrm{~mm}$ or deeper ( $P$ value $.001)$, as well as number of teeth with pocket depths of $7 \mathrm{~mm}$ or deeper (P value .011) (Table 4).

Table 3:-Distribution of Responses to Individual OHIP Items

\begin{tabular}{|l|l|l|l|l|l|}
\hline OHIP 14 & $\begin{array}{l}\text { Never } \\
\mathrm{N}(\%)\end{array}$ & $\begin{array}{l}\text { Hardly ever } \\
\mathrm{N}(\%)\end{array}$ & $\begin{array}{l}\text { Occasionally } \\
\mathrm{N}(\%)\end{array}$ & $\begin{array}{l}\text { Fairly often } \\
\mathrm{N}(\%)\end{array}$ & $\begin{array}{l}\text { Very often } \\
\mathrm{N}(\%)\end{array}$ \\
\hline $\begin{array}{l}\text { trouble pronouncing } \\
\text { words }\end{array}$ & $23(92.0)$ & $0(0.0)$ & $1(4.0)$ & $0(0.0)$ & $1(4.0)$ \\
\hline worsened sense of taste & $18(72.0)$ & $1(4.0)$ & $4(16.0)$ & $1(4.0)$ & $0(0.0)$ \\
\hline painful aching & $2(8.0)$ & $3(12.0)$ & $15(60.0)$ & $2(8.0)$ & $3(12.0)$ \\
\hline uncomfortable to eat & $7(28.0)$ & $2(8.0)$ & $9(36.0)$ & $3(12.0)$ & $4(16.0)$ \\
\hline felt nausea & $20(80.0)$ & $1(4.0)$ & $4(16.0)$ & $0(0.0)$ & $0(0.0)$ \\
\hline felt nervous & $9(36.0)$ & $2(8.0)$ & $5(20.0)$ & $1(4.0)$ & $6(24.0)$ \\
\hline $\begin{array}{l}\text { diet has been } \\
\text { unsatisfactory }\end{array}$ & $15(60.0)$ & $1(4.0)$ & $6(24.0)$ & $1(4.0)$ & $1(4.0)$ \\
\hline interrupted meals & $13(52.0)$ & $0(0.0)$ & $10(40.0)$ & $0(0.0)$ & $1(4.0)$ \\
\hline difficult to relax & $7(28.0)$ & $7(28.0)$ & $9(36.0)$ & $1(4.0)$ & $0(0.0)$ \\
\hline embarrassment & $12(42.0)$ & $0(0.0)$ & $8(32.0)$ & $2(8.0)$ & $3(12.0)$ \\
\hline $\begin{array}{l}\text { irritable with other } \\
\text { people }\end{array}$ & $11(44.0)$ & $2(8.0)$ & $7(28.0)$ & $1(4.0)$ & $4(16.0)$ \\
\hline $\begin{array}{l}\text { difficulty doing usual } \\
\text { jobs }\end{array}$ & $16(64.0)$ & $3(12.0)$ & $4(16.0)$ & $1(4.0)$ & $0(0.0)$ \\
\hline less satisfaction & $13(52.0)$ & $2(8.0)$ & $7(28.0)$ & $2(8.0)$ & $1(4.0)$ \\
\hline unable to function & $21(84.0)$ & $0(0.0)$ & $4(16.0)$ & $0(0.0)$ & $0(0.0)$ \\
\hline
\end{tabular}

Table 4:-Pearson Correlation of OHIP-14 Subscales with CAL/PD

\begin{tabular}{|c|c|c|c|c|c|c|c|}
\hline & & $\begin{array}{l}\text { number } \\
\text { of teeth } \\
\text { with site } \\
\text { of } \\
\text { CAL=3 }\end{array}$ & $\begin{array}{l}\text { number } \\
\text { of teeth } \\
\text { with site } \\
\text { of CAL } \\
=4\end{array}$ & $\begin{array}{l}\text { number } \\
\text { of teeth } \\
\text { with site } \\
\text { of } \\
\text { CAL } \geq 5\end{array}$ & $\begin{array}{l}\text { number } \\
\text { of teeth } \\
\text { with site } \\
\text { of } P D \geq 3\end{array}$ & $\begin{array}{l}\text { number } \\
\text { of teeth } \\
\text { with site } \\
\text { of } P D \geq 5\end{array}$ & $\begin{array}{l}\text { number } \\
\text { of teeth } \\
\text { with site } \\
\text { of } \mathrm{PD} \geq \\
7\end{array}$ \\
\hline \multirow{2}{*}{$\begin{array}{l}\text { Functional } \\
\text { limitation }\end{array}$} & Pearson Correlation & .161 & .376 & .095 & .172 & .389 & .364 \\
\hline & $\mathrm{P}$ value & .441 & .064 & .652 & .411 & .055 & .074 \\
\hline \multirow[t]{2}{*}{ Physical pain } & Pearson Correlation & .281 & $.604^{* *}$ & $.406^{*}$ & -.114 & $.560^{* *}$ & $.567^{* * 4}$ \\
\hline & P value & .173 & .001 & .044 & .586 & .004 & .003 \\
\hline \multirow{2}{*}{$\begin{array}{l}\text { Psychological } \\
\text { discomfort }\end{array}$} & Pearson Correlation & .015 & .394 & .212 & -.115 & $.402^{*}$ & .252 \\
\hline & $\mathrm{P}$ value & .942 & .051 & .309 & .585 & .046 & .223 \\
\hline \multirow{2}{*}{$\begin{array}{l}\text { Physical } \\
\text { disability }\end{array}$} & Pearson Correlation & .268 & $.444^{*}$ & .198 & -.205 & $.396^{*}$ & .269 \\
\hline & $\mathrm{P}$ value & .196 & .026 & .342 & .324 & .050 & .193 \\
\hline \multirow{2}{*}{$\begin{array}{l}\text { Psychological } \\
\text { disability }\end{array}$} & Pearson Correlation & .313 & $.616^{* *}$ & $.469^{*}$ & -.059 & $.601^{* *}$ & $.559^{* *}$ \\
\hline & $P$ value & .128 & .001 & .018 & .780 & .001 & .004 \\
\hline \multirow{2}{*}{$\begin{array}{l}\text { Social } \\
\text { disability }\end{array}$} & Pearson Correlation & .254 & $.499^{*}$ & .355 & .018 & $.558^{* *}$ & .378 \\
\hline & $\mathrm{P}$ value & .220 & .011 & .082 & .933 & .004 & .063 \\
\hline
\end{tabular}




\begin{tabular}{|l|l|l|l|l|l|l|l|}
\hline \multirow{2}{*}{ Handicap } & Pearson Correlation & .030 & .379 & .160 & -.192 & $.414^{* *}$ & .318 \\
\cline { 2 - 7 } & P value & .888 & .062 & .445 & .358 & .039 & .121 \\
\hline $\begin{array}{l}\text { Oral health } \\
\begin{array}{l}\text { Impact } \\
\text { profile-14 }\end{array}\end{array}$ & Pearson Correlation & .248 & $.608^{* *}$ & .356 & -.092 & $.606^{* *}$ & $.497^{* *}$ \\
\cline { 2 - 7 } & P value & .232 & .001 & .080 & .663 & .001 & .011 \\
\hline
\end{tabular}

\section{Discussion:-}

Quality of life is increasingly acknowledged as a valid, appropriate and significant indicator of service need and intervention outcomes in contemporary public health research and practice. Health related QoL measures, including objective and subjective assessments, are especially useful for evaluating efforts to prevent disabling chronic diseases and assessing their effectiveness ${ }^{15}$. Assessing the consequences of impaired oral health from the patient's perspective has emerged as an important research $\operatorname{area}^{16}$. This has led to an increase in the use of patient-centered oral health status measures, primarily attempting to measure the impact of oral health on $\mathrm{QoL}^{17}$.

This study had included 25 patients with different degrees of severity of periodontal disease. The objective of the study was to assess the impact of periodontal health status on quality of life among subjects diagnosed with periodontal disease, in a university setting in Riyadh. The OHIP-14 is a commonly used index for evaluation of the negative effects of periodontal disease on the patients' quality of life ${ }^{8}$. The Arabic version of the OHIP-14 was used in this study to assess such effect, and it had been shown in a previous study in Jordan to be valid and reliable ${ }^{11}$.

A number of clinical studies have utilized the OHIP-14 to assess the impact of periodontal disease on the quality of life ${ }^{6,8,10}$. In a study by Borges, et al., the Brazilian OHIP-14 index was used to assess the oral health-related quality of life on a sample of 24 patients with varying degrees of periodontal conditions ${ }^{12}$. It was concluded that there was a statistically significant correlation between the OHIP- $14 \mathrm{Br}$ total score and the degree of loss of periodontal structures.

In the present study, it was found that the impact of periodontal disease on the patient's quality of life was statistically significant in two domains, physical pain and psychological disability. The significant correlation between disease severity and physical pain (P value .004) is in agreement with that reported by AlHabashneh, et al., $2012,{ }^{11}$ Borges, et al., 2013, ${ }^{12}$ and $\mathrm{Ng} \&$ Leung $2006^{18}$. The negative impact on psychological disability ( $P$ value $.001)$ was also in agreement with the results presented by AlHabashneh, et al., $2012^{11}$ and Ng \& Leung $2006^{18}$. The severity of periodontal disease in this current study was not significantly correlated with functional limitation. This is in contrast to the results reported by $\mathrm{Ng} \&$ Leung $2006^{18}$, and Araujo, et al., 2010 ${ }^{10}$, which showed that periodontal disease had a statistically significant effect on functional limitation.

In general, the total OHIP-14 scores were significantly related to the number of teeth with pocket depths of $5 \mathrm{~mm}$ or deeper ( $P$ value .001). The same correlation was also found with the number of teeth with clinical attachment loss of $4 \mathrm{~mm}\left(P\right.$ value .001), which is in agreement with that reported by Bernabe'and Marcenes (2010) ${ }^{19}$.

The small sample size in this present study is considered a major limitation. This can be attributed to time restrictions and difficulties finding patients that fit the inclusion and exclusion criteria of the study. This study, however, to the best of our knowledge, is the first to assess the impact of periodontal disease on the quality of life using the Arabic version of the OHIP-14 index in Saudi Arabia. We highly recommend conducting a similar study on a larger sample size to assess the impact of periodontal disease on quality of life on a larger scale, and obtain better generalizable results.

Within the limitation of our study, it can be concluded that by using the Arabic version of the OHIP -14 index, periodontal disease had a negative impact on quality of life. These findings suggest that the use of this index, as well as other patient-centered outcome measures, has significant implications in periodontology, including treatment planning and evaluation of treatment results.

\section{Acknowledgements:-}

We would like to thank Dr .RolaAlHabashneh, Dr.Yousef S. Khader, and Dr. ShathaSalameh for providing us with the Arabic short-form version of the Oral Health Impact Profile (OHIP-14) questionnaire. Our great thanks and appreciation also go to Mr. Nasser Al Meflahi for his help on the statistical analysis. 


\section{References:-}

1. Guile EE. Periodontal status of adults in central saudi arabia. Community Dentistry and Oral Epidemiology 1992; 20: 159-160.

2. Jansson H, Wahlin $\AA$, Johansson $\mathrm{V}$, Akerman S, Lundegren N, Isberg PE, et al. Impact of periodontal disease experience on oral health-related quality of life. J Periodontol. 2014 Mar;85(3):438-45.

3. Beikler T, Flemmig TF. Oral biofilm-associated diseases: trends and implications for quality of life, systemic health and expenditures. periodontology 2011;55(1): 87-103.

4. O' Dowd LK, Durham J, McCracken GI, Preshaw PM. Patients' experiences of the impact of periodontal disease. Journal of Clinical Periodontology 2010; 37: 334-339.

5. Raphael D. Rukholm E, Brown I, Hill-Bailey P, . Donato E. The quality of life profile-Adolescent version: Background, description, and initial validation. Journal of Adolescent Health 1996; 19:366-375.

6. Jowett AK, Orr M, Rawlinson A, Robinson PG. Psychosocial impact of periodontal disease and its treatment with 24-h root surface debridement. journal of clinical periodontology2009;36:413-418.

7. Allen PF. Assessment of oral health related quality of life. Health and Quality of Life Outcomes 2003; 1:40

8. Slade GD. Derivation and validation of a short-form oral health impact profile. Community Dentistry and Oral Epidemiology 1997; 25:284-290.

9. Needleman I, McGrath C, Floyd P, Biddle A.. Impact of oral health on the life quality of periodontal patients. Journal of Clinical Periodontology 2004; 31:454-457.

10. Araújo AC, Gusmão ES, Batista JEM, Cimões R. impact of periodontal disease on quality of life. Quintessence International 2010; 41:111-118.

11. Al Habashneh R, KhaderYS, Salameh S. Use of the Arabic version of oral health impact profile-14 to evaluate the impact of periodontal disease on oral health-related quality of life among Jordanian adults. Journal of Oral Science 2012; 54:113-120.

12. Borges Tde F, Regalo SC, Taba M Jr, Siéssere S, Mestriner W Jr, Semprini M. Changes in Masticatory performance and quality of life in individuals with chronic periodontitis. J Periodontol. 2013 Mar;84(3):325-31

13. Wong R, $\mathrm{Ng} \mathrm{S}$, Corbet E, Leung W.. Non-surgical periodontal therapy improves oral health-related quality of life. journal of clinical periodontology 2012; 39:53-61.

14. Palma PV, Caetano PL, Leite IC.Impact of Periodontal Diseases on Health-Related Quality of Life of Users of the Brazilian Unified Health System. Int J Dent. 2013;2013:150357

15. Hennessy, C. H. et al., 1994. Measuring health-related quality of life for public health surveillance. Public Health Rep, Volume 109, p. 665-672.

16. Buck D, Newton JT. Non-clinical outcome measures in dentistry: publishing trends 1988-98. Community Dentistry and Oral Epidemiology 2001; 29: 2-8.

17. Birch S. Ismail AI. Patient preferences and the measurement of utilities in the evaluation of dental technologies. Journal of Dental Research 2002;81: 446-450.

18. Ng SK, Leung WK. Oral health-related quality of life and periodontal status. Community Dentistry and Oral Epidemiology 2006; 34:114-122.

19. Bernabe'E, Marcenes W. Periodontal disease and quality of life in British adults. Journal of Clinical Periodontology 2010; 37968-972. 